\title{
Modeling the behaviour of inflation deviations from the target
}

\author{
Andros Gregoriou ${ }^{a}$, Alexandros Kontonikas ${ }^{\mathrm{b}}$ \\ ${ }^{a}$ Brunel Business School, Economics and Finance Section, Brunel University, Uxbridge, \\ Middlesex, UB8 39H, UK \\ ${ }^{b}$ Department of Economics, University of Glasgow, Adam Smith Building, \\ Glasgow, G12 8RT, UK
}

\begin{abstract}
This study tests for and models non-linearities in inflation deviations from the target in five OECD countries that adopted inflation targeting over the 1990s. Our tests reject the linearity hypothesis and we show that the exponential smooth transition autoregressive (ESTAR) model is capable of capturing the non-linear behavior of inflation misalignments. The extent of inflation deviations from the target varies across the OECD countries, with countries that consistently undershoot the target having a rapid adjustment process, whereas countries that overshoot the target have a slower revision back to equilibrium. Out-of-sample forecasts from the ESTAR model outperform the Markov regime-switching model.
\end{abstract}

JEL classification: E31; E52; C5.

Keywords: Inflation; Inflation targeting; STAR models.

\footnotetext{
* Corresponding author: Andros Gregoriou, Tel: +44(0) 1895 269770, e-mail andros.gregoriou@brunel.ac.uk
} 


\section{Introduction}

In the 1990 s a number of countries shifted to a new monetary policy framework by announcing a quantitative target for inflation. The reason for this shift was the unsatisfactory performance under previous regimes (Svensson, 1997). Consequently, during the 1990s inflation has been lower and less volatile (see among others, Kontonikas, 2004). Inflation targeting (IT) central banks typically manipulate the shortrun interest rate instrument so that the ultimate policy target, inflation, remains on track. In other words, in the context of a successful IT regime inflation misalignments from the announced target should be eliminated through appropriate policy interventions. In this paper, we propose an alternative hypothesis where the speed of adjustment towards the target increases, the greater the deviation of inflation from the target. This is consistent with non-linear monetary policy reaction functions, where there is a stronger response to inflation when it is further from the target. Orphanides and Wieland (2000) point out that if the central bank assigns at least some weight to output stabilization, the output stabilization objective will dominate when inflation is within the targeted zone, and inflation stabilization will dominate when inflation deviations from the target become large. Due to the volatility costs associated with adjusting interest rates to control inflationary pressures, monetary authorities may not react when inflation is close to the target. Hence, inflation may follow a random walk close to the target. Conversely, the more distant inflation is from the target, the greater the probability that the Central Bank will take remedial action ${ }^{1}$.

The concept that the speed of adjustment increases as a function of inflation deviations from the target is captured by utilizing the STAR (Smooth Transition Autoregressive) family of models. The STAR model allows for the possibility that inflation misalignments may be in some intermediate state between regimes where the nature of adjustment varies with the extent of deviation from the target (Granger and Terasvirta, 1993; Terasvirta, 1994). Depending on the form of the function that controls the

\footnotetext{
${ }^{1}$ Martin and Milas (2004) provide empirical evidence for the UK indicating that while interest rates are relatively passive when inflation is close to the target, there is an increasingly aggressive response as inflation deviations from the target become larger.
} 
transition between regimes, a logistic STAR (LSTAR) or an exponential STAR (ESTAR) may be specified. The STAR framework has been used to model non-linearities in exchange rates (see among others, Sarantis, 1999) and to analyze inflation in high inflation economies (Byers and Peel, 2000²). Arghyrou et al. (2005) estimate non-linear inflation models of the STAR variety using data from the UK and find that inflation adjusts more quickly when prices are further from the steady state. Gregoriou and Kontonikas (2006) show that inflation deviations from the target in a number of inflation targeting countries are characterized by non-linear (ESTAR) stationarity indicating successful targeting implementation. Beyond STAR models, Markov regime-switching models have also been employed in the literature to investigate regime switching in inflation (Evans and Wachtel, 1993). Altavilla and Ciccarelli (2007) compare the out-ofsample forecasting properties of various linear and non-linear inflation models and find that the ESTAR model generally does well with both US and Euro-area data, outperforming the random walk model at different time horizons, and dominating the Markov regime-switching model.

The aim of this paper is to test for and model non linearities in inflation deviations from the target in five OECD countries that participated in inflation targeting from the 1990s. Our findings are important for at least three reasons. First, to our knowledge, with the exception of Gregoriou and Kontonikas (2006) who focused on the stationarity property of the series, there has been no previous attempt to empirically model inflation deviations from the target. Our second contribution is that our models allows for the possibility that inflation misalignments from the target can be characterized by a non-linear process. Specifically, when inflation is far away from the target, the model permits the speed of adjustment to be greater than when inflation is close to the target. Our third contribution is that we compare the predictive power of the ESTAR model versus the Markov regimeswitching model which provides the main alternative non-linear formulation for inflation deviations from the target.

\footnotetext{
${ }^{2}$ Byers and Peel (2000) estimate ESTAR models for three inflationary episodes (Germany in the early 1920s, and post-World War II in Argentina and Brazil) and find that as a result of highly volatile inflationary shocks each economy moved from an equilibrium low-inflation rate to a high-inflation state.
} 
The remainder of the paper is organised as follows. In the following section, Section 2 we outline the econometric specification and estimation methodology. Section 3 discusses the data. Section 4 provides a discussion of our empirical results and finally, Section 5 concludes.

\section{Specification and estimation of STAR models}

The degree of misalignment between inflation and its predetermined target is computed as:

$e_{t}=\pi_{t}-\pi_{t}^{*}$

where $\pi_{t}^{*}$ is the inflation target and $\pi_{t}$ is the actual inflation rate.

Consider two possible regimes comprising a pure 'small' and pure 'large' adjustment of inflation deviations from the target. Following Granger and Terasvirta (1993) we write a STAR model of order $k$, for $e_{t}$ as:

$e_{t}=\theta_{0}+\theta_{1}{ }^{\prime} x_{t}+\left(\delta_{0}+\delta_{1}{ }^{\prime} x_{t}\right) F\left(e_{t-d}\right)+w_{t}$

where $x_{t}=\left(e_{t-1}, e_{t-2}, \ldots e_{t-k}\right), \theta_{1}=\left(\theta_{1}, \theta_{2}, \ldots \theta_{k}\right)^{\prime}, \delta_{1}=\left(\delta_{1}, \delta_{2}, \ldots \delta_{k}\right)^{\prime}, w_{t} \sim \operatorname{iid}\left(0, \sigma^{2}\right), F($. is the continuous transition function, $e_{t-d}$ is the switching variable, and $d$ is the delay parameter. $F($.$) is a monotonically increasing function with F(-)=0$ and $F()=1$ which yields a non-linear asymmetric adjustment.

Consider the following Logistic STAR (LSTAR) function:

$F\left(e_{t-d}\right)=\left\{1+\exp \left[-a\left(e_{t-d}-c\right)\right]\right\}^{-1}$

where $a$ measures the smoothness of transition from one regime to another and $c$ is some threshold value for $e$ that indicates the halfway point between the two regimes. 
The LSTAR model assumes that different regimes may have different dynamics and that adjustment takes place in every period but the smoothness of adjustment varies with the extent of the deviation from equilibrium. The transition function of LSTAR is monotonically increasing in $e_{t-d}$ and yields asymmetric adjustment towards equilibrium in the model. Moreover, $F(.) \rightarrow 0$ as $e_{t-d} \rightarrow-\propto$ and $F(.) \rightarrow 1$ as $e_{t-d} \rightarrow+\propto$ thus $F($.$) is bounded between 0$ and 1 where $F()=$.0.5 if $e_{t-d}=c$. The smaller is $a$, the smoother the transition. In the extreme, $a=0$ means that $F($.$) becomes a constant and so$ (2) becomes a linear model. On the other hand, as $a \rightarrow \infty$ there is an even sharper transition at $e_{t-d}=c$ where $F($.$) jumps from 0$ to 1 .

Terasvirta and Anderson (1992) define the Exponential STAR (ESTAR) function as:

$$
F\left(e_{t-d}\right)=1-\exp \left[-a\left(e_{t-d}-c\right)^{2}\right]
$$

where, as previously, a measures the speed of transition from one regime to another and $c$ is some threshold value for $e$ which indicates the halfway point between the two regimes. The ESTAR function in (4) defines a transition function about $c$ where $F($.$) is$ still bounded between 0 and 1 .

The initial testing for the presence of non-linearities in $e_{t}$ is based on three stages. First, a linear autoregressive model for $e$ is specified in order to determine the lag length $k$. The lag length selection is based on the Schwarz information criteria and the Ljung-Box statistic for serial correlation. The residuals are saved from the chosen autoregressive model and denoted as $v$. Second, having determined $k$, the next stage is to test for the presence of non-linearities. This is done through the estimation of

$v_{t}=\beta_{0}+\beta_{1}{ }^{\prime} x_{t}+\beta_{2}{ }^{\prime} x_{t} e_{t-d}+\beta_{3}{ }^{\prime} x_{t} e^{2}{ }_{t-d}+\beta_{4}{ }^{\prime} x_{t} e^{3}{ }_{t-d}+w_{t}$

where the linearity test is on the null hypothesis $H_{0}: \beta_{2}{ }^{\prime}=\beta_{3}{ }^{\prime}=\beta_{4}{ }^{\prime}=0$. Equation (5) is estimated across a range of values for $d$ where the smallest $\mathrm{p}$-value attached to the 
linearity test determines $d$ in the estimation of (2). The final stage of the non-linearity test is to determine which smooth transition model - LSTAR or ESTAR - is appropriate for the data. This is done by running the following sequence of nested tests.

$H_{04}: \beta_{4}^{\prime}=0$

$H_{03}: \beta_{3}{ }^{\prime}=0 / \beta_{4}{ }^{\prime}=0$

$H_{02}: \beta_{2}{ }^{\prime}=0 / \beta_{4}{ }^{\prime}=\beta_{3}{ }^{\prime}=0$

Rejection of (6) implies selecting the LSTAR model. If we accept (6) and (7) we choose the ESTAR model. Accepting (6) and (7) and rejecting (8) leads to an LSTAR model. However, Granger and Terasvirta (1993) and Terasvirta (1994) show that application of this sequence of tests may lead to incorrect conclusions, because the higher order terms of the Taylor expansion used in deriving these tests are disregarded ${ }^{3}$. They therefore recommend that we should compute the p-values of all the F tests of (6)-(8) and make the choice of STAR model on the basis of the lowest p-value.

\section{Data}

Our dataset comprises of five OECD countries, United Kingdom, Canada, Sweden, Australia and New Zealand that have announced a quantitative inflation target. Table 1 provides a description of targeting implementation in our sample countries. Since IT regimes typically monitor the evolution of annual inflation, we measure inflation, $\pi_{t}$, as the annual difference of the natural $\log$ of the price index, $P$, that is relevant for monetary policy decisions. Hence, $\pi_{t}$ is defined as $\pi_{t}=100 *\left(\ln P_{t}-\ln P_{t-12}\right)$ in United Kingdom, Canada and Sweden, which provide monthly price series; $\pi_{t}=100 *\left(\ln P_{t}-\ln P_{t-4}\right)$ in Australia and New Zealand, where quarterly price series are available. The starting point in the estimation sample for each country corresponds to the date when IT was adopted,

\footnotetext{
${ }^{3}$ For more details see Terasvirta (1994) pages 211-212.
} 
while the end-point is the third quarter of 2007, November 2007 with quarterly, monthly data, respectively.

\section{[INSERT TABLE 1 HERE]}

\section{Results}

\subsection{Unit Root Tests}

The application and estimation of the STAR models require stationary time series. Furthermore, as Gregoriou and Kontonikas (2006) point out, successful targeting implementation implies that deviations of inflation from the target should follow a stationary process ${ }^{4}$. Explosive deviations of inflation above or below the targeted value indicate that the central bank is unsuccessful in its primary mandate, which is to control inflation. Table 2 columns two and three present the results from the standard linear Augmented Dickey Fuller test (ADF; Said and Dickey, 1984) for inflation deviations from the target, $e_{\mathrm{t}}$. The results indicate that in all sample countries the null-unit root hypothesis cannot be rejected at the conventional significance levels. This result is independent of the ADF regression model's deterministic component specification ${ }^{5}$. Across all sample countries, the trend term (results not shown here but available upon request) is not statistically significant at the $5 \%$ level of significance or less. Significance of the trend term would imply that inflation deviations from the target in absolute value are growing deterministically over time which would be inconsistent with successful

\footnotetext{
${ }^{4}$ As Svensson (1997) argues, IT implies 'base drift' of the price level, suggesting that the price level has a unit root and inflation is stationary. Since the value of the target itself is deterministic -controlled by the monetary authorities- Gregoriou and Kontonikas (2006) take Svensson's argument one step further by claiming that successful IT implementation implies stationary inflation deviations from the targeted value.

${ }^{5}$ Since we use annual inflation data observed $k$ times per year for a moving average of order $(k-1)$ an MA(k-1), structure is theoretically imposed on our series. Therefore, as a robustness check we augmented the ADF regression model with an MA(11) term in the monthly regressions, and an MA(3) term in the quarterly regressions. Using the MacKinnon critical values (MacKinnon, 1996) the results (not shown but available upon request) indicate that with the exception of New Zealand (constant) where the null-unit root is rejected at the 5\% level of significance, in all other cases the unit root hypothesis cannot be rejected. Furthermore, Hall (1989) demonstrates that in the presence of MA(q) innovations the limiting distribution of the instrumental variable estimator converges to the distribution tabulated by Dickey and Fuller (1979). Thus, overall, it appears that the unit root evidence in our sample countries is robust to the presence of a moving average term.
} 
targeting implementation. The ADF test results are only mildly affected by the lag-length selection criterion ${ }^{6}$.

Gregoriou and Kontonikas (2006) argue that finding that inflation deviations from the target are non-stationary should be considered a puzzle, indicating either non-successful inflation targeting or inadequate unit root testing procedures. In order to tackle the second possibility, in addition to the standard ADF test we also considered the $\mathrm{Ng}$ and Perron (2001) test. The Ng and Perron (2001) $\mathrm{MZ}_{\alpha}$ test modifies the Phillips (1987) and Phillips and Perron (1988) $Z_{\alpha}$ test in a number of ways in order to increase the test's size and power. This testing procedure ensures that non-rejections of the null-unit root are not due to a low probability of rejecting a false null hypothesis, while rejections are not related to size distortions ${ }^{7}$. The results from the $\mathrm{Ng}$ Perron test shown in columns four and five of Table 2 indicate that the null-unit root hypothesis can only be rejected at the $5 \%$ level in two cases (Australia, New Zealand) in the models with intercept only. Thus, overall, the puzzling unit root evidence still prevails.

However, it is well known that potential failure to reject non-stationarity may be the result of linear unit root tests not being very powerful when the true adjustment process is non-linear (Kapetanios et al. 2003). Gregoriou and Kontonikas (2006) employ the nonlinear unit root test of Kapetanios et al (2003) which assumes that the adjustment of inflation towards the predetermined target is characterized by a symmetric non-linear process. Using a sample ending at 2004, they find that once non-linear behaviour is taken

\footnotetext{
${ }^{6}$ When the reduction criterion is employed instead of the Modified Akaike Criterion to select the lag-length in the ADF regression model, the unit root hypothesis can be rejected at the $5 \%$ level only in the cases of Australia (constant, constant and trend) and New Zealand (constant). To select the lag length with the reduction criterion, we set an upper bound of lagged difference terms and tested down by sequentially removing the last lag until a significant (at 5\% level) lag was reached. The upper bound is calculated as $k_{\max }=\operatorname{int}\left(12 /(T / 100)^{1 / 4}\right)$, where int(x) denotes an integer part of x. See Hayashi $(2000$, p.594) for a discussion of the selection of this upper bound.

${ }^{7} \mathrm{Ng}$ and Perron (2001) demonstrate that their testing procedure leads to improvement in the power of the unit root test in the presence of an autoregressive root which is close to but less than unity, and reduction of size distortions in the presence of a large negative moving average root in the differenced series. They also argue that, when specifying the leg-length in unit root tests, standard information criteria such as the Akaike criterion tend to choose too few lags in the presence of a large negative moving average root in the error term. This generates additional size distortions. Ng and Perron (2001) suggest that the autoregressive truncation lag should be chosen using the Modified Akaike Information Criterion in an effort to avoid size distortions while maintaining power.
} 
into account inflation deviations from the target are stationary. Table 2 columns six and seven show the results from the Kapetanios et al. (2003) non-linear unit root test. It appears that the results of Gregoriou and Kontonikas (2006) are robust to extending the sample period by three years, since in all cases the null-unit root hypothesis is strongly rejected $^{8}$. Hence, given the finding of non-linear stationarity, the variable $\left(e_{t}\right)$ used in all subsequent estimations is the level of the misalignments of inflation from its target value.

\section{[INSERT TABLE 2 HERE]}

\subsection{Tests for linearity and STAR model selection}

Table 3 displays the tests for non- linearity for $e_{t}$ for the 5 OECD countries in our sample. The Ljung-Box statistic suggests white noise residuals for all autoregressive models. Following the selection of the lag length $k$ for each autoregressive process, the delay parameter $d$ is constrained to be $1 \leq d \leq 8$. Using 0.05 as a threshold $p$-value, the test rejects linearity, classifying the series as non-linear. We can therefore proceed to build non-linear models for $e_{t}$. The tests for the choice between LSTAR and ESTAR models are shown in Table 4. Using the hypothesis tests outlined in equations (6)-(8), the results indicate that the ESTAR model is the most appropriate non-linear model in all cases. The ESTAR model implies that governments adjust inflation from high to low levels towards the middle ground in a similar fashion.

\section{[INSERT TABLES 3 and 4 HERE]}

\subsection{Estimates of the non-linear models}

The ESTAR models are estimated by non-linear least squares, using the Marquandt algorithm. Granger and Terasvirta (1993, pp 123-124) and Terasvirta (1994) point out that estimation of the parameter $a$ may cause particular problems, such as "overestimation". Therefore, following their recommendation we scale the argument of

\footnotetext{
${ }^{8}$ The unit root test of Kapetanios et al. (2003) assumes a non-linear Exponential Smooth Transition Autoregressive (ESTAR) process for inflation deviations from the target. The results from non-linearity tests in section 4.2 fully support this requirement.
} 
the transition function $\mathrm{F}($.$) by dividing it by \sigma^{2}(e)$. Hence, the scaled transition function used in the estimation of the ESTAR model is:

$$
F\left(e_{t-d}\right)=1-\exp \left\{-a\left(1 / \sigma^{2}(e)\right)\left(e_{t-d}-c\right)^{2}\right\}
$$

On the basis of this scaling, we have used $a=1$ as an initial value, and the sample mean as a starting value for the parameter $\mathrm{c}$. The estimates of the autoregressive model are used as initial values for the $\theta$ and $\delta$ parameters.

The parameter estimates together with the diagnostic tests are reported in Table 5. The standard errors of the non linear models are smaller then the standard errors of the linear models for all the series suggesting, that the non linear models provide a better fit of the data. The Jarque-Bera normality test indicates that the residuals are normally distributed for all the countries in our data set. Hence the non linearities in inflation misalignments with respect to the predetermined target are not the outcome of any outliers in the data. The residuals are tested for first order serial correlation and ARCH effects. The p-values (using 0.05 as the threshold) reject the presence of serial correlation and the presence of $\mathrm{ARCH}$ type of non-linearity in the residuals for all series.

In all cases $a$ is correctly signed and significantly different from zero at the 5\% level. The magnitude of $a$ varies among countries, with the UK, Australia and New Zealand exhibiting a speed of adjustment towards the target relatively higher, compared to Sweden and Canada ${ }^{9}$. UK has the highest speed of adjustment, and as the results in the last column of Table 1 indicate, it is also the most successful targeter, in terms of its average inflation deviation from the target being almost equal to zero. A potential scenario to explain our results is that countries that undershoot the target (UK, Australia, New Zealand) are induced to adopt aggressive monetary policies to control inflation leading to a relatively quick elimination of the discrepancies, while countries that overshoot the target (Canada, Sweden) exhibit slow adjustment due to less pressure for

\footnotetext{
${ }^{9}$ Notice that the scaling of $\left(e_{t-d}-c\right)$ in the transition function makes it possible to judge the size of $a$ (Granger and Terasvirta, 1993, pp 123, 153).
} 
controlling inflation since inflation is consistently lower then the target. Hence, despite the fact that the target is symmetric in all countries so that deviations above and below target are treated in the same manner, it appears that consistent overshooting or undershooting of the target affects the subsequent speed of adjustment. ${ }^{10}$

Table 5 also reports estimates of the halfway points, c, or thresholds between the two pure regimes. In all cases c was insignificantly different from the mean adjustment rate, $\bar{e}$. This suggests that observations are distributed roughly equally between the left-hand and right-hand tails of their respective exponential functions. ${ }^{11}$

\section{[INSERT TABLE 5 HERE]}

\subsection{Out of sample forecasts}

In order to assess the predictive power of the ESTAR models, we compare their out of sample forecasts with the Markov regime-switching model (Hamilton, 1989) which provides the main alternative non-linear specification. The out-of-sample forecasts were computed by re-estimating all models up until the end of 2004 and then multi-step ahead forecasts were generated for the time period 2005-2007. ${ }^{12}$ Table 6 reports the root mean squared errors (RMSEs) for the computed forecasts of the two non-linear models. In comparing the forecasting performance of the two non-linear models the ESTAR model produces more accurate forecasts in all countries over the 2005-2007 prediction period. This is not surprising given that the estimates of the transition parameter are relatively low for all countries, contrary to the Markov regime-switching model which assumes a sharp regime switch. Our results regarding the forecasting performance of the ESTAR

\footnotetext{
${ }^{10}$ Note we have not provided simulated critical values of the ESTAR models represented in Table 5 in the presence of MA errors that are imposed in the non-linear model as a result of the transformation of annual inflation rates to monthly and quarterly series (see footnote 5 for further details). We believe this is not necessary given that our $t$-statistics for the transition parameter are in excess of 2.46 in all cases. Therefore, following Arghyrou et al. (2005) we use conventional critical values of the $t$-distribution for our hypothesis testing in the presence of MA errors.

${ }^{11}$ Note the non linear results should be treated with caution given that if we estimate inflation deviations from the target in first differences (results not reported and available upon request) we obtain similar empirical results, indicating that the STAR models have low explanatory power.

${ }_{12}$ We would like to thank TSP International (http://www.tspintl.com) for providing the Markov regimeswitching model code for the out of sample forecasts.
} 
model are in agreement with evidence for the US and the Euro-area by Altavilla and Ciccarelli (2007).

\section{[INSERT TABLE 6 HERE]}

\section{Conclusions}

In this paper, we model inflation deviations from the target within a sample of five OECD countries that adopted targeting regimes over the 1990s. We present strong evidence of non-linearities in the adjustment process for all five countries in our sample. These inflation misalignments are classified as ESTAR models for all the countries. The estimated ESTAR models pass all the main diagnostic tests and provide a reasonable description of the non-linearity found in inflation deviations from the target. In addition the ESTAR models outperform the alternative non-linear formulation provided by the Markov regime-switching model in an out of sample forecasting contest. The estimates of the transition parameter indicate that the speed of adjustment differs across countries. While the UK, Australia and New Zealand feature a relatively rapid speed of adjustment towards the target, Canada and Sweden exhibit a much smoother transition to the inflation target. Our results suggest that the adjustment process is almost twice as fast in countries which undershoot the target than countries that consistently overshoot it.

An explanation for those findings may be related to the pressure exercised on central banks to control accelerating inflation. This pressure ultimately originates in the dislike of the general public to rising prices, while falling prices are considered a good (or at least not bad) outcome. The increasing level of debt in an environment of low inflation in many economies verifies the lack of understanding of the potential threats from falling prices. Central banks, though operationally independent from political control, may feel constrained by their public mandate since they derive their authority from elected governments, which dictate the goals they should pursue through legislation. Hence, the aversion to higher prices results into a stronger reaction to upward deviations of inflation from the target and a subsequent faster speed of adjustment towards it. Our view is that given the dangers from deflationary pressures, such as depressed revenues and higher real 
debt burden, misalignments below the target should be treated as seriously and rapidly as those above the target.

\section{References}

Altavilla, C., and M. Ciccarelli (2007), "Inflation forecasts, monetary policy and unemployment dynamics. Evidence from the US and the Euro Area", European Central Bank Working Paper Series No. 725

Arghyrou, M., Martin C., and C. Milas (2005), "Non-linear inflation dynamics: evidence from the UK", Oxford Economic Papers 57, 51-69.

Byers, J.D., and D.A. Peel (2000), "Non-linear dynamics of inflation in high inflation economies", The Manchester School 68, 23-37.

Dickey, D.A. and W.A. Fuller (1979), "Distribution of the estimators for autoregressive time series with a unit root", Journal of the American Statistical Association 74, 427-431.

Evans, M., and P. Wachtel (1993), "Inflation regimes and the sources of inflation uncertainty", Journal of Money, Credit and Banking 25, 475-511.

Granger, C.J. and T. Terasvirta (1993), "Modelling non linear economic relationships", Oxford University Press.

Gregoriou, A. and A. Kontonikas (2006), "Inflation targeting and the stationarity of inflation: new results from an ESTAR unit root test", Bulletin of Economic Research 58, 309-322.

Hall, A. (1989), "Testing for a unit root in the presence of moving average errors", Biometrika 76, 49-56.

Hamilton, J. (1989), "A new approach to the economic analysis of nonstationary time series and the business cycle", Econometrica 57, 357-384.

Hayashi, F. (2000), “Econometrics”, Princeton University Press.

Kapetanios, G., Shin, Y. and A. Snell (2003), "Testing for a unit root in the non-linear STAR framework", Journal of Econometrics 112, 359-379.

Kontonikas, A. (2004), "Inflation and inflation uncertainty in the United Kingdom, Evidence from GARCH modeling”, Economic Modelling 21, 525-543.

MacKinnon, J. (1996), "Numerical distribution functions for unit root and cointegration tests", Journal of Applied Econometrics 11, 601-618. 
Martin, C. and C. Milas (2004), "Modelling monetary policy: inflation targets in practice", Economica 71, 209-221.

$\mathrm{Ng}$, S. and P. Perron, (2001), "Lag length selection and the construction of unit root tests with good size and power", Econometrica 69, 1519-1554.

Orphanides, A. and V. Wieland (2000), "Inflation zone targeting", European Economic Review 44, 1351-1387.

Phillips, P.C. (1987), "Time series regressions with a unit root", Econometrica 55, 277302.

Phillips, P.C. and P. Perron (1988), "Testing for a unit root in time series regression", Biometrika 75, 335-346.

Said, S. and D. Dickey (1984), "Testing for unit roots in autoregressive-moving average models of unknown order", Biometrika 71, 599-607.

Sarantis, N. (1999), "Modeling non-linearities in real effective exchange rates", Journal of International Money and Finance 18, 27-45.

Svensson, L. (1997), "Monetary policy and inflation targeting", NBER Reporter Winter 1997/98, 5-8.

Terasvirta, T. and H.M. Anderson (1992), "Characterising nonlinearities in business cycles using smooth transition autoregressive models", Journal of Applied Econometrics 7, 119-139.

Terasvirta, T. (1994), "Specification, estimation, and evaluation of smooth transition autoregressive models", Journal of American Statistical Association 89, 208-218. 
Table 1: Inflation targeting implementation in the sample countries

\begin{tabular}{|c|c|c|c|c|}
\hline Countries & Target Variable & $\begin{array}{c}\text { Date of } \\
\text { Adoption or } \\
\text { Modification }\end{array}$ & $\begin{array}{l}\text { Target Range } \\
\text { or Value }\end{array}$ & $\begin{array}{c}\text { Average } \\
\text { deviation of } \\
\text { inflation from } \\
\text { the target }\end{array}$ \\
\hline \multirow{2}{*}{ United Kingdom } & $\begin{array}{l}\text { Retail Price Index } \\
\text { Excluding Mortgage } \\
\text { Interest Payments }\end{array}$ & $\begin{array}{l}\text { October } 1992 \\
\text { May } 1997\end{array}$ & $\begin{array}{l}1-4 \% \\
2.5 \%\end{array}$ & \multirow[t]{2}{*}{$0.04 \%$} \\
\hline & $\begin{array}{c}\text { Harmonized } \\
\text { Consumer Price Index }\end{array}$ & January 2004 & $2 \%$ & \\
\hline Canada & $\begin{array}{l}\text { Core Consumer Price } \\
\text { Index }\end{array}$ & $\begin{array}{c}\text { February } 1991 \\
\text { January } 1992 \\
\text { June } 1994 \\
\text { January } 1995 \\
\end{array}$ & $\begin{array}{c}3-5 \% \\
2-4 \% \\
1.5-3.5 \% \\
1-3 \% \\
\end{array}$ & $-0.49 \%$ \\
\hline Sweden & Consumer Price Index & January 1995 & $2 \%$ & $-0.81 \%$ \\
\hline \multirow{2}{*}{ Australia } & $\begin{array}{c}\text { Treasury Underlying } \\
\text { Consumer Price Index }\end{array}$ & September 1994 & \multirow{2}{*}{$2-3 \%$} & \multirow{2}{*}{$0.19 \%$} \\
\hline & Consumer Price Index & September 1998 & & \\
\hline New Zealand & $\begin{array}{l}\text { All Groups Consumer } \\
\text { Price Index }\end{array}$ & $\begin{array}{l}\text { January } 1990 \\
\text { January } 1991 \\
\text { January } 1992 \\
\text { January } 1993 \\
\text { January } 1997\end{array}$ & $\begin{array}{c}3-5 \% \\
2.5-4.5 \% \\
1.5-3.5 \% \\
0-2 \% \\
0-3 \%\end{array}$ & $0.51 \%$ \\
\hline
\end{tabular}

Note: The inflation targets in all sample countries are expressed in terms of the annual growth rate of the relevant price index. The Core Consumer Price Index in Canada excludes eight of the most volatile components prices (fruit, vegetables, gasoline, fuel oil, natural gas, mortgage interest, intercity transportation, and tobacco products) as well as the effect of changes in indirect taxes on the remaining components. Prior to May 2001, the Bank of Canada used the CPI excluding food, energy, and the effect of changes in indirect taxes as its measure of core CPI. In Australia, the target variable was the Treasury underlying Consumer Price Index up to June quarter 1998 and the CPI since with an adjustment for the effects of tax and health policy changes on the CPI. 
Table 2: Unit root test results for the deviation of inflation from the target

\begin{tabular}{|c|c|c|c|c|c|c|}
\hline \multirow{3}{*}{ Countries } & \multicolumn{4}{|c|}{ Linear } & \multirow{2}{*}{\multicolumn{2}{|c|}{$\begin{array}{c}\text { Non-linear } \\
\text { ADF t-test statistic }\end{array}$}} \\
\hline & \multicolumn{2}{|c|}{ ADF t-test statistic } & \multicolumn{2}{|c|}{ Ng Perron $\mathrm{MZ}_{\alpha}$ test statistic } & & \\
\hline & Constant & $\begin{array}{c}\text { Constant and } \\
\text { Trend }\end{array}$ & Constant & $\begin{array}{c}\text { Constant and } \\
\text { Trend }\end{array}$ & Constant & $\begin{array}{c}\text { Constant and } \\
\text { Trend }\end{array}$ \\
\hline United Kingdom & $-2.81[12]$ & $-2.35[13]$ & $-0.99[12]$ & $-5.68[12]$ & $\begin{array}{c}-8.23[3]^{* *} \\
(0.003)\end{array}$ & $\begin{array}{c}-9.72[1]^{* *} \\
(0.003)\end{array}$ \\
\hline Canada & $-2.48[13]$ & $-2.45[13]$ & $-2.7[13]$ & $-12[13]$ & $\begin{array}{c}-3.01[3]]^{* *} \\
(0.004)\end{array}$ & $\begin{array}{c}-4.26[1]^{* *} \\
(0.004)\end{array}$ \\
\hline Sweden & $-1.3[12]$ & $-1.79[12]$ & $-2.52[12]$ & $-3.25[12]$ & $\begin{array}{c}-9.21[3] * * \\
(0.003)\end{array}$ & $\begin{array}{c}-11.60[1] * * \\
(0.002)\end{array}$ \\
\hline Australia & $-2.34[0]$ & $-2.28[0]$ & $-8.86[0] *$ & $-9.11[0]$ & $\begin{array}{c}-7.40[0] * * \\
(0.003)\end{array}$ & $\begin{array}{c}-8.76[0] \\
(0.003)\end{array}$ \\
\hline New Zealand & $-2.83[4]$ & $-2.61[4]$ & $-11.12[4] *$ & $-12.54[4]$ & $\begin{array}{c}-4.26[1] \\
(0.004)\end{array}$ & $\begin{array}{c}-6.27[1]{ }^{* *} \\
(0.004)\end{array}$ \\
\hline
\end{tabular}

Note: Figures in the square brackets represent the number of lagged difference terms in the unit root testing regressions, chosen by Modified Akaike Criterion. The reported test statistics test the null hypothesis that inflation contains a unit root. Figures in the round brackets represent the $p$ value of the $t$-statistic obtained through a bootstrap simulation with 10,000 replications. **, * indicate rejection of the null-unit root hypothesis at 1,5 level of significance. 
Table 3: Tests for non-linearities

\begin{tabular}{|c|c|c|c|c|}
\hline Countries & K & d & p-value & Q(1) \\
\hline United Kingdom & 3 & 1 & 0.003 & 0.473 \\
\hline Canada & 3 & 1 & 0.003 & 0.375 \\
\hline Sweden & 3 & 1 & 0.004 & 0.319 \\
\hline Australia & 3 & 1 & 0.004 & 0.417 \\
\hline New Zealand & 3 & 1 & & 0.420 \\
\hline
\end{tabular}

Note: Table 3 reports the linearity tests of $e_{t}$ for five OECD countries. The null of non linearity is based on equation (5). The column headed ' $p$-value' corresponds to the test $\mathrm{H}_{0}$ where the null is linearity. It should be noted that the Schwartz criteria is used to determine the lag length $k$ of the autoregressive process. The residuals from the autoregressive processes were then saved. Having determined $k$, a range of delay parameters $(d \leq 1 \leq 8)$ were employed. The value of $d$ chosen is that which gives rise to the lowest $p$-value of the linearity test using the data for the residuals of the autoregressive process. The linearity test is a variable-deletion $F$ test on the restriction applied to equation (5). The column headed $Q(1)$ refers to the $p$ value associated with the Ljung-Box Q statistic for serial correlation among the residuals.

Table 4: Specification of the Non-Linear Model

\begin{tabular}{|l|l|l|l|l|}
\hline Countries & $H_{04}$ & $H_{03}$ & $H_{02}$ & Type of Model \\
\hline United Kingdom & 0.153 & $0.004 \#$ & 0.170 & ESTAR \\
\hline Canada & 0.150 & $0.005 \#$ & 0.172 & ESTAR \\
\hline Sweden & 0.140 & $0.004 \#$ & 0.163 & ESTAR \\
\hline Australia & 0.147 & $0.005 \#$ & 0.170 & ESTAR \\
\hline New Zealand & 0.135 & $0.004 \#$ & 0.173 & ESTAR \\
\hline
\end{tabular}

Note: Table 4 reports the variable deletion tests portrayed in equations (6), (7) and (8). \# denotes the lowest p-value associated with the variable-deletion tests and therefore the determination of the relevant STAR model. The values of $\mathrm{k}$ and $\mathrm{d}$ are reported in Table 2 . 
Table 5: Estimates of the ESTAR Models

$$
\begin{aligned}
& \text { United Kingdom } \\
& e_{t}=0.49+0.721 e_{t-1}+\left(0.73+0.825 e_{t-1}\right) \\
& \begin{array}{llll}
(0.14) & (0.22) & (0.20) & (0.27)
\end{array} \\
& \mathrm{x}\left[1-\exp \left\{-4.14\left(1 / \sigma^{2}(e)\right)\left(e_{t-1}-0.469\right)^{2}\right\}\right] \\
& \text { (1.00) }
\end{aligned}
$$

$\mathrm{S}=0.434, \mathrm{Q}(1)=0.670, \mathrm{ARCH}(1)=0.176, \operatorname{NORM}(2)=0.144, \mathrm{~S} / \mathrm{SL}=0.823$

\section{Australia}

$e_{t}=0.52+0.678 e_{t-1}+\left(0.78+0.821 e_{t-1}\right)$

$$
\begin{gathered}
(0.14) \quad(0.22) \quad(0.24) \quad(0.31) \\
x\left[1-\exp \left\{-3.84\left(1 / \sigma^{2}(e)\right)\left(e_{t-1}-0.469\right)^{2}\right\}\right] \\
(1.00)
\end{gathered}
$$

$\mathrm{S}=0.423, \mathrm{Q}(1)=0.634, \mathrm{ARCH}(1)=0.171, \operatorname{NORM}(2)=0.139, \mathrm{~S} / \mathrm{SL}=0.994$

New Zealand

$e_{t}=0.45+0.635 e_{t-1}+\left(0.756+0.765 e_{t-1}\right)$

$$
\begin{gathered}
\left(\begin{array}{lll}
0.12) & (0.20) & (0.41) \\
\mathrm{x} & {\left[1-\exp \left\{-4.04\left(1 / \sigma^{2}(e)\right)\left(e_{t-1}-0.472\right)^{2}\right\}\right.}
\end{array}\right] \\
(1.00)
\end{gathered}
$$

$\mathrm{S}=0.431, \mathrm{Q}(1)=0.521, \mathrm{ARCH}(1)=0.163, \operatorname{NORM}(2)=0.135, \mathrm{~S} / \mathrm{SL}=0.878$ 


$$
\begin{aligned}
& \text { Canada } \\
& e_{t}=0.47+0.633 e_{t-1}+\left(0.65+0.706 e_{t-1}\right) \\
& \begin{array}{llll}
(0.11) & (0.05) & (0.11) & (0.15)
\end{array} \\
& \mathrm{x}\left[1-\exp \left\{-2.56\left(1 / \sigma^{2}(e)\right)\left(e_{t-1}-0.443\right)^{2}\right\}\right]
\end{aligned}
$$

\section{Sweden}

$e_{t}=0.53+0.609 e_{t-1}+\left(0.70+0.683 e_{t-1}\right)$

$$
\begin{array}{llll}
(0.14) & (0.03) & (0.11) & (0.15)
\end{array}
$$$$
\mathrm{x}\left[1-\exp \left\{-2.59\left(1 / \sigma^{2}(e)\right)\left(e_{t-1}-0.463\right)^{2}\right\}\right]
$$

$\mathrm{S}=0.279, \mathrm{Q}(1)=0.572, \operatorname{ARCH}(1)=0.182, \operatorname{NORM}(2)=0.163, \mathrm{~S} / \mathrm{SL}=0.728$

Note: Table 5 represents non linear estimation of equation (2) by the Gauss Newton method. Values under regression coefficients are standard errors. Q(1) is the P-value for first order serial correlation (Ljung-Box $\mathrm{Q}$ statistic). ARCH(1) is the P-value for the first order autoregressive conditional heteroscedasticity (Engle F-test). NORM(2) is the P-value for the Jarque-Bera normality test. S/SL is the ratio of the standard errors for the non-linear and linear models.

Table 6: Root mean squared errors over the forecast period, 2005-2007

\begin{tabular}{|c|c|c|}
\hline Country & ESTAR Model & Markov Switching Model \\
\hline UK & 0.013 & 0.019 \\
\hline Australia & 0.019 & 0.023 \\
\hline New Zealand & 0.024 & 0.027 \\
\hline Australia & 0.023 & 0.034 \\
\hline Canada & 0.033 & 0.047 \\
\hline Sweden & 0.037 & 0.061 \\
\hline
\end{tabular}

Note: Table 6 represents root mean squared forecast errors of the ESTAR and the Markov regimeswitching model for each country, over the period 2005-2007. 